\title{
Kinematical Analysis on Xiangrong LIU Backward Sliding Shot Putting Technique
}

\author{
Ting Long and Jihe Zhou* \\ ChengDu sport Institute, China \\ ${ }^{*}$ Corresponding author
}

\begin{abstract}
Purposes: Analysis of the Chinese women's shot player Xiangrong LIU 2016 national track and field throwing group race (Xipu station) champion throwing action, revealing the law of shot put. Procedures: Application data engineering method - with two JVC GC-PX10AC cameras were placed in the direction of throwing and positive right, two cameras, the main axis of the angle of about $90^{\circ}$, shooting frequency of $50 \mathrm{~Hz}$. Using Signal TEC 3D software to analyze the kinematic parameters. Methods: Three - dimensional video analysis method. Result: The study of kinematic parameters refinement, the whole throw is divided into five times, four stages. Conclusions: Pre-swing acceleration, sliding step, buffer the three stages of the center of gravity speed, shot speed are improved. The last stage of force, the center of gravity velocity decreased, the shot speed increased. T4 moment shoulder hip angle of $109.5^{\circ}$, "beyond the device" is better; $\mathrm{T} 5$ time shot speed $12.5 \mathrm{~m} / \mathrm{s}$ to be improved, shot height $1.97 \mathrm{~m}$ reasonable, shot angle $35.89^{\circ}$ smaller.
\end{abstract}

Keywords-female shot put; back sliding; kinematic analysis

\section{PREFACE}

Women's shot put is the advantage of our track and field projects, the late 1980s to the early 1990s to the peak, but in recent years, China's women's shot put in a state of landslides in the world are not ideal. Shot Put from the beginning of the jump to the shot so far back to the slide step Shot and rotation Shot Put the era, Although the shot of the world record holder Barnes using rotary shots to achieve $23.12 \mathrm{~m}$ results, but found that women shot back to slide the way to push the shots still dominate, and get good results, Women's Shot Putting World Record Holders Natalia Lisovovskaya is also using back-to-slide shots. In the whole shot during the throwing

process to the center of gravity to drive the shot speed, in the final force stage shot height greatly improved, in order to maintain a stable center of gravity decline. Based on the relevant literatures at home and abroad, it is found that there is more research on the speed, height and angle of the shot force in the last stage of shot. However, there are few studies on the shot speed and the center of gravity of the whole throwing process. The last stage of the entire throw process is the next stage and the last effort to prepare. Although the shot of the shot speed is the biggest impact on the throwing factors, but the study of the throwing process of the shot speed and center of gravity speed is also particularly important. In this paper, Xiangrong LIU (the first throwing game) as the research object, On its 2016 national track and field throwing group race (Xipu) station shot put the best results in the pre-final third (results: $17.88 \mathrm{~m}$ ) for video analysis. The paper analyzes the causes of the differences in the results and improves the technical problems. It aims to provide the theoretical basis and technical reference for the training and competition of women's shot put.

\section{PURPOSE}

Improve the performance of women's shot put in China, to provide theoretical basis and technical reference for women's shot put training.

\section{RESEARCH SUBJECTS AND METHODS}

\section{A. Object of Study} LIU.

Chinese athletic team woman shot contestant Xiangrong

TABLE I. XIANGRONG LIU BASIC INFORMATION

\begin{tabular}{lccccccc}
\hline Name & Date of birth & Height & Weight & Technical type & Sports level & Best results & Analytical results \\
\hline XiangrongLIU & $1988-6-6$ & $185 \mathrm{~cm}$ & $118 \mathrm{~kg}$ & back sliding & national level & $19.18 \mathrm{~m}$ & $17.88 \mathrm{~m}$ \\
\hline
\end{tabular}

\section{B. Research Methods}

Literature search method, video analysis method, data statistics method

\section{ANALYSIS OF THE RESUltS OF THE STUDY}

In order to better kinematically analyze the throwing technique, this paper divides the shrapnel into four shots, four stages:

5 moments:
Left leg swing backwards: The left hand of the athlete (Swing legs) moves backwards from the ground.

Right foot from the ground phase: Athlete right foot off the ground (T2).

Right foot to the ground: Athlete's right foot time (T3).

Left foot to the ground: Athlete left foot time (T4).

Shot shot when the phase: Shot shot time (T5).

4 stages: 
The first stage(T1 T2): Pre-swing acceleration stage,

Second stage(T2 T3): Sliding stage,

The third stage(T3 T4): Buffer stage,

The fourth stage(T4 T5): The last stage of force.

The meaning of time and stage division: According to the law of the movement of the shrapnel in the back, the whole story is pushed toward the zero. Analyze the meaning of each stage and the athlete's quality at this stage. The main influencing factors of each stage are discussed, and the whole backward sliding step shot is analyzed and evaluated.

\section{A. Pre-swing Acceleration Phase Analysis}

TABLE II. PRE-SWING ACCELERATION PHASE RELATED PARAMETERS

\begin{tabular}{lll}
\hline Time name & center of gravity speed & shot ball speed \\
\hline T1 time & $0.38 \mathrm{~m} / \mathrm{s}$ & $0.82 \mathrm{~m} / \mathrm{s}$ \\
T2 time & $1.71 \mathrm{~m} / \mathrm{s}$ & $1.88 \mathrm{~m} / \mathrm{s}$ \\
\hline
\end{tabular}

Pre-swing acceleration phase: T1 time: center of gravity speed: $0.38 \mathrm{~m} / \mathrm{s}$; shot ball speed: $0.82 \mathrm{~m} / \mathrm{s}$, T2 time: center of gravity speed: $1.71 \mathrm{~m} / \mathrm{s}$; shot ball speed: $1.88 \mathrm{~m} / \mathrm{s}$. The pre swing stage is 1.22s. Prepare the posture to reduce the body center of gravity, lengthen the shot before the shot of the force of the distance, while the back and support legs stretch muscles easy to force. Through the pre-pendulum acceleration stage, the center-of-gravity velocity and shot pitch speed are improved, and the center-of-gravity velocity increases greatly.

\section{B. Sliding Stage Analysis}

TABLE III. SLIDING STAGE RELATED PARAMETERS

\begin{tabular}{lcc}
\hline Time name & Center of gravity speed & shot ball speed \\
\hline T2 time & $1.71 \mathrm{~m} / \mathrm{s}$ & $1.88 \mathrm{~m} / \mathrm{s}$ \\
T3 time & $1.89 \mathrm{~m} / \mathrm{s}$ & $1.71 \mathrm{~m} / \mathrm{s}$ \\
\hline
\end{tabular}

Sliding stage: T2 time: center of gravity speed: $1.71 \mathrm{~m} / \mathrm{s}$; shot ball speed: $1.88 \mathrm{~m} / \mathrm{s}$. T3 time: center of gravity speed: $1.89 \mathrm{~m} / \mathrm{s}$; shot ball speed: $2.71 \mathrm{~m} / \mathrm{s}$. Sliding stage with $0.10 \mathrm{~s}$. Through the sliding step, the center of gravity speed, shot to further improve the rate of shot to improve the larger. Slip step on the body posture remains relatively unchanged, keep the back, increase the force and distance on the shot put, prepare for the buffer phase.

\section{Buffer Stage Analysis}

TABLE IV. BUFFER STAGE RELATED PARAMETER

\begin{tabular}{llllll}
\hline Time name & $\begin{array}{l}\text { Shoulder } \\
\text { angle }\end{array}$ & hip & $\begin{array}{l}\text { Center of } \\
\text { speed }\end{array}$ & gravity & $\begin{array}{l}\text { Shot } \\
\text { speed }\end{array}$ \\
\hline T3 time & & $1.89 \mathrm{~m} / \mathrm{s}$ & $2.71 \mathrm{~m} / \mathrm{s}$ \\
T4 time & $109.5^{\circ}$ & $2.16 \mathrm{~m} / \mathrm{s}$ & $3.34 \mathrm{~m} / \mathrm{s}$ \\
\hline
\end{tabular}

Buffer stage: T3 time: center of gravity speed: $1.89 \mathrm{~m} / \mathrm{s}$; shot ball speed: $2.71 \mathrm{~m} / \mathrm{s}$. T4 moment: center of gravity speed: $2.16 \mathrm{~m} / \mathrm{s}$; shot ball speed: $3.34 \mathrm{~m} / \mathrm{s}$; Shoulder hip angle: $109.5^{\circ}$; Buffer stage with $0.16 \mathrm{~s}$. The center of gravity of the buffer stage, the shot speed has increased, the larger the increase of shot. Buffer stage mainly rely on the right knee buckle, right leg side pedal to form the hip, send hip. Trunk twist to the left side of the body muscles in a state of tension, in the T4 moment to form a shoulder hip angle of $109.5^{\circ}$. Forced active muscle group was pulled to the appropriate length, on the one hand to store elastic potential energy, on the one hand to give the appropriate length of muscle, so that muscle contraction to produce the maximum strength. Good "beyond the device" to store the elastic potential for the last effort to improve the speed of the shot to prepare.

\section{The Last Stage of Force Analysis}

TABLE V. THE LAST STAGE OF FORCE RELATED PARAMETERS

\begin{tabular}{lllll}
\hline $\begin{array}{l}\text { Time } \\
\text { name }\end{array}$ & $\begin{array}{l}\text { Center of } \\
\text { gravity speed }\end{array}$ & $\begin{array}{l}\text { shot ball } \\
\text { speed }\end{array}$ & Shot height & Shot angle \\
\hline T4 time & $2.16 \mathrm{~m} / \mathrm{s}$ & $3.34 \mathrm{~m} / \mathrm{s}$ & & \\
T5 time & $1.79 \mathrm{~m} / \mathrm{s}$ & $12.05 \mathrm{~m} / \mathrm{s}$ & $1.97 \mathrm{~m}$ & $35.89^{\circ}$ \\
\hline
\end{tabular}

The last stage of force: T4 moment: center of gravity speed: 2.16 m / s; shot ball speed: $3.34 \mathrm{~m} / \mathrm{s}$; T5 moment: center of gravity speed: $1.79 \mathrm{~m} / \mathrm{s}$; shot speed: $12.05 \mathrm{~m}$ / s; Shot angle of $35.89 \mathrm{o}$; shot height of $1.97 \mathrm{~m}$, the last force stage with $0.26 \mathrm{~s}$. The final stage of gravity center of gravity to reduce the rate of a substantial increase in shot .According to the conservation of energy, the total mechanical energy of the shot is the sum of its kinetic energy and potential energy, and it is equal to the athlete's ability to accelerate the shot. At the same time should improve the coordination of muscle capacity, trunk rotation efficiency, reduce the last stage of energy loss, improve the shot shot speed.

The last stage of force is the most important stage of the whole throw. From Table 5 we can see that shot shot at this stage the maximum increase in the rate of shooting, while the shot speed is the impact of the shot from the maximum impact of the factors. Although the athletes in the final force stage shot height greatly improved, but compared with other outstanding athletes, the shooting speed is still a big increase in space.(World outstanding athlete results: $19.60 \mathrm{~m}$; shot speed: $13.12 \mathrm{~m} / \mathrm{s}$ )[6].The speed of the shot depends on the magnitude of the force acting on the shot and the distance of action[6]. Shooting speed of $70 \%$ to $85 \%$ depends on the rotation of the shoulder strap and the extension of the right hand[4] The shot angle is smaller than the best shot angle $\left(37^{\circ} \sim 41^{\circ}\right)$. The angle of the shot depends on the direction of the force of throwing the shot[6]. The shot angle is small, resulting in a decrease in flight distance. The height of the shot is more reasonable, the height of the shot depends on the height of the athlete and the length of the arm. Shot angle of the height of the impact of each other, shot height increased, the best shot angle but reduced.

\section{CONCLUSION AND RECOMMENDATIONS}

5.1 Pre-swing stage and step-by-step step shot to improve the ideal. Buffer stage and the final forced stage shot height is not enough.

5.2 Athletes shot smaller angle, increase the shot speed, shot angle will increase. Shot height increase, the best shot angle will be reduced, the shot height is more reasonable.

5.3 Athletes shot less speed, resulting in throwing distance is short. Improve the energy transfer efficiency of lower limbs, torso and upper limbs; Control the shot to throw the direction, so that the trajectory in the same vertical level. 
5.4 Finally forced the stage pedal stretch force is not enough, Should be combined with shot throwing characteristics to strengthen the strength of training, applied to the special training, the development of body strength.

5.5 The whole shot throwing process center of gravity speed, shot the ball speed law is reasonable, but the last stage of force shot rate increase is not enough.

\section{REFERENCES}

[1] Lai Qicai. Zhang Jun throw Shot Kinematic analysis [D]. Chengdu Sport University, 2012.

[2] Lu xiaowei.A Comparative Study on the Technical Characteristics of Shot and Back Sliding Shot [J]; Journal of Hebei Normal University (Natural Science Edition)

[3] Zhang yingbo.The Characteristics of Rotating Shot Put and Its Biomechanical Parameters Comparison with Back Sliding Shot Put [J]. Athletics, 1994,04: 20-24.

[4] Sports Biomechanics [M]: Improvement of Sports Achievement and Prevention of Sports Injury/[US] Zhaizi Erqi Ji editor: Lu Aiyun translation. - Beijing: People 's Sports Press, 2003

[5] Exercise Physiology [M]/ Wang Ruiyuan, editor in chief. - Beijing: People's Sports Publishing House, 2011 (2013.2. Reprint)

[6] Sports Biomechanics [M]/ Lu Aiyun editor - Beijing: People's Sports Publishing House, 2009 (2014.2. Reprint)

[7] Zheng Fuqiang.Study on the Temporal and Spatial Characteristics of the Lower Extremity of the Backward Sliding Shot [A]. China Sport Science Society .2015 Summary of the Tenth National Sports Science Conference [2] [C] China Sports Science Society: 2015: 3.

[8] Liu Zhiqiang. The 12th National Games women's shot putter last force technology kinematics research [D]. Shanxi University,2014.

[9] Wang Liping, Yu Qun, Song Mingwei, Zhao Dong.Journal of Shandong Sports Science and Technology, 2011, (03): 28-31.

[10] Liao Chunlong, Zhang Yan, Bai Guangbin, Research on the Speed Rhythm of Chinese Elite Female Shot Putters Backward Sliding Shot Putting Technique [J] .National Business (Theoretical Studies), 2011, (05): 111-113.

[11] Xin Feng, Li Jin Gang.Journal of Shandong Sports Science and Technology, 2010, (01): 9-11. (In Chinese) [J]. 